\title{
Development and preclinical evaluation of $\left[{ }^{68} \mathrm{Ga}\right] \mathrm{Ga}-$ Alb-FAPtp-01, a novel tumour-associated fibroblast activation protein tracer for PET imaging of xenograft glioma
}

Jia-Jia Lin

Chang Gung Memorial Hospital

Chia-Pao Chuang

National Taiwan University

Jia-Yu Lin

National Taiwan University

Feng-Ting Huang

National Taiwan University

chiun-wei Huang ( $\sim$ steincafe77@gmail.com )

Center for advanced molecular imaging and translation, Chang Gung Memorial Hospital

https://orcid.org/0000-0001-6017-9581

\section{Research Article}

Keywords: FAP, Gallium-68, Glioblastoma, PET/CT imaging, Tracer development

Posted Date: May 19th, 2021

DOI: https://doi.org/10.21203/rs.3.rs-500662/v1

License: (c) (i) This work is licensed under a Creative Commons Attribution 4.0 International License.

Read Full License 


\section{Abstract \\ Purpose}

Dynamic changes in tumour-associated fibroblast activation protein (FAP) expression in tumours of different stages may be helpful for prognostic evaluation and treatment response monitoring, making this protein a promising surveillance biomarker for timely diagnosis of malignant tumours and effective planning of patient care. Thus, novel FAP-PET imaging tracers were developed and evaluated for the diagnosis of xenograft glioma tumours.

\section{Methods}

To prospectively verify the prognostic value of the developed FAP tracers, $\left[{ }^{68} \mathrm{Ga}\right] \mathrm{Ga}-\mathrm{FAPtp}$ and $\left[{ }^{68} \mathrm{Ga}\right] \mathrm{Ga}-$ Alb-FAPtp-01, measurements of FAP expression and cell uptake and specific binding assays were conducted in U87MG glioma cells. Dynamic/static PET/CT scans were acquired for tumour targeting studies in vivo and in comparison with the reference tracer $\left[{ }^{68} \mathrm{Ga}\right] \mathrm{Ga}-\mathrm{FAPI}-04$ to evaluate diagnostic efficacy. Tumour autoradiography and immunohistochemistry images were acquired to confirm the tracer distribution within the tumour to determine whether it was in accordance with the pathologic data.

\section{Results}

Both $\left[{ }^{68} \mathrm{Ga}\right] \mathrm{Ga}-\mathrm{FAPI}-04$ and $\left[{ }^{68} \mathrm{Ga}\right] \mathrm{Ga}$-FAPtp demonstrated marked tumour uptake and comparable pharmaceutical profiles in $1 \mathrm{~h}$ dynamic PET scans, and [ $\left.{ }^{68} \mathrm{Ga}\right] \mathrm{Ga}-F A P t p$ had marginally favourable tumour uptake and less kidney and liver uptake. However, both tracers demonstrated rapid clearance from tumours. Thus, the optimized rationally designed FAP-targeting PET tracer $\left[{ }^{68} \mathrm{Ga}\right] \mathrm{Ga}-A l b-F A P t p-01$, with albumin binding capability, demonstrated prominent longitudinal tumour uptake in tumour xenografts and displayed significant tumour-to-background contrast over time. The tracer uptake values and $\mathrm{T} / \mathrm{M}$ ratio were $1.775 \pm 0.179 \mathrm{SUV}$ and $\mathrm{T} / \mathrm{M}=5.9,1.533 \pm 0.222 \mathrm{SUV}$ and $\mathrm{T} / \mathrm{M}=6.7$, and $1.425 \pm$ 0.204 SUV and T/M $=9.5$, respectively, at $1 \mathrm{~h}, 2 \mathrm{~h}$ and $3 \mathrm{~h}$. Major organs, such as the heart $(0.504 \pm$ $0.125 \% \mathrm{ID} / \mathrm{g})$, muscle $(0.156 \pm 0.043 \% \mathrm{ID} / \mathrm{g})$ and brain $(0.119 \pm 0.039 \% \mathrm{ID} / \mathrm{g})$, all displayed comparatively low levels of tracer uptake.

\section{Conclusion}

Its improved tumour uptake and pharmacokinetics suggest that the $\left[{ }^{68} \mathrm{Ga}\right] \mathrm{Ga}$-Alb-FAPtp-01 tracer can noninvasively detect FAP activation in vivo, permitting a precise definition of its roles in tumours of different stages and yielding insights regarding novel FAP-targeted radiotherapeutic strategies at the molecular level. 


\section{Introduction}

Malignant tumours can usually be distinguished from nonmalignant cells, such as immune and endothelial cells, and extracellular matrix components by their ability to modulate the peritumoural environment [1-4]. Thus, the dynamic, constantly changing stromal tumour microenvironment (TME) provides cues for assessing tumour proliferation and invasion and the ability to metastasize to distant sites. In contrast, most localized tumours exhibit limited diffuse growth. Thus, the interactions between the tumour and the TME and even microvascular proliferation status, which indicates tumour growth and progression, are essential for tumour characterization.

Distinct from normal fibroblasts, cancer-associated fibroblasts (CAFs) in the TME express high levels of a unique protein called fibroblast activation protein (FAP), which has been recognized as a potential prognostic marker [5-6]. FAP, also known as FAPa or seprase, is a membrane-bound type II serine protease and a member of the $S 9$ family of proline-specific proteases, which includes dipeptidyl peptidase IV (DPPIV), DPP8, DPP9, and prolyl endopeptidase (PREP) [7]. FAP possesses both dipeptidy peptidase and endopeptidase activities. Importantly, the expression of FAP in adult mammals is usually low in most normal tissues but elevated in activated fibroblasts during tissue remodelling at sites of inflammation, such as sites of rheumatoid arthritis, osteoarthritis, fibrosis of the heart and liver, and in a variety of tumour-promoting environments [8-11].

Although the molecular mechanism underlying the contribution of FAP to tumour severity remains elusive, intense studies of potential FAP-targeted inhibitors, diagnostic agents and therapeutic interventions have been expanding in recent decades [12-14]. The rapidly growing field of FAP-targeting agent development, including but not limited to antibodies, chimaeric antigen receptor T cells, immunoconjugates, peptide-drug complexes and small molecules for the inhibition of FAP enzyme activity, has received increasing attention. Among these agents, small molecules such as FAP inhibitors (FAPIs) have had the most promising results from the perspective of FAP-expressing tumour cell binding, internalization, efflux, tumour xenograft accumulation and theranostic application in patients [15-19].

Noninvasive positron emission tomography (PET) imaging with suitable radioligands may quantify the distribution of biomarkers of interest through the measurement of radioactivity profiles in living subjects. Such radiopharmaceutic approaches may reveal the network of molecular mechanisms underlying diseases and assist in the development and evaluation of effective therapies. The development of optimal suitable PET tracers is especially challenging because they must satisfy a wide array of chemical, biochemical, and pharmacological requirments. To reduce unnecessary radioexposure, an important aspect of PET radiotracer development is to consider variations in specific binding affinities and concentrations across species in relevant native tissues.

Therefore, in the current investigation, a prototype peptide-based FAP-specific PET tracer, $\left[{ }^{68} \mathrm{Ga}\right] \mathrm{Ga}$-FAPtp, based on the structure of a potent FAP inhibitor (known as UAMC-1110) [20], were designed, characterized and optimized for use as novel FAP-targeted diagnostic agents and potential theranostic 
agents. In contrast to the original quinoline-based moiety, peptide amide bond core structures with an additional short PEGylating linker were contemporaneously adopted. Furthermore, to enhance the plasma retention time, the optimized $\left[{ }^{68} \mathrm{Ga}\right] \mathrm{Ga}$-Alb-FAPtp-01 tracer with an endogenous albumin-binding moiety, 4p-chlorophenyl butyric acid [21], was designed to improve pharmacokinetics and was tested in glioma xenograft models. Characteristics including FAP binding specificity and affinity, were validated by in vitro cell uptake assays and biolayer interferometry (BLI), and preclinical pharmacokinetics were determined in a U87MG xenograft model by small-animal PET/CT imaging, ex vivo histochemical staining and biodistribution studies. These first proof-of-concept tracers are unique in that they can be effectively synthesized through the standard solid-phase peptide synthesis (SPPS) procedure without any sophisticated chemical methods. Thus, the peptide probes can be easily accessed via custom order from any certificated peptide vendor in any amount requested. Importantly, the cyclic chelator DOTA can be utilized as the functional component for ${ }^{68} \mathrm{Ga}$ isotope radiolabelling for PET imaging and, possibly, for endoradiotherapy interventions involving labelling with therapeutic isotopes, such as ${ }^{90} \mathrm{Y}$ and ${ }^{177} \mathrm{Lu}$.

\section{Materials And Methods}

\section{General}

All commercially available chemical reagents were analytical grade, purchased from Aldrich (St. Louis, MO, USA) and used without further purification. The FAPI-04 precursor was purchased from KriSan Biotech Co. (Tainan, Taiwan), a PICS/GMP-certified pharmaceutical company. The FAP-targeting peptides DOT-PEG 8 -Gly-Pro-Trp-Gly-Pro (4,4-F 2 (DOTA-FAPtp) and DOTA-Lys (4-p-chlorophenyl) butyric acid)-PEG ${ }_{8}$ Gly-Pro-Trp-Gly-Pro (4,4-F ${ }_{2}$ ) (Alb-FAPtp-01) (Fig. 1) were designed by us and purchased from Mission Biotech (Taipei, Taiwan). The ${ }^{68} \mathrm{GaCl}_{3}$ solution was produced by elution with $0.05 \mathrm{~N} \mathrm{HCl}$ through a ${ }^{68} \mathrm{Ge} /{ }^{68} \mathrm{Ga}$ generator (ITG, Germany). The radiochemical purity of the radiolabelling product was determined on an analytical reverse-phase HPLC system equipped with a dual ultraviolet absorbance detector (Waters 2487, Waters, Milford, MA, USA) using a Phenomenex (Torrance, CA, USA) synergi $4 \mathrm{~m}$ Hydro-RP $80 A^{\circ}(150 \times 3 \times 4.6 \mathrm{~mm}, 4 \mu \mathrm{m})$. The flow rate was $1 \mathrm{~mL} / \mathrm{min}$, with the mobile phase starting with $98 \%$ solvent $A(0.1 \%$ trifluoroacetic acid (TFA) in water) and $2 \%$ solvent B ( $0.1 \%$ TFA in acetonitrile) (0-2 min) and transitioning to $35 \%$ solvent $A$ and $65 \%$ solvent $B$ over 30 min.

\section{Radiochemistry}

The details of the ${ }^{68} \mathrm{Ga}$ labelling procedures have been reported previously, with a radiochemical purity over $95 \%$ [22-23]. Briefly, [ ${ }^{68} \mathrm{Ga}$ ] Ga-acetate was prepared by adding $555-370 \mathrm{MBq} / \mathrm{mL}^{68} \mathrm{GaCl}^{3+}$ to $250 \mu \mathrm{L}$ of $0.1 \mathrm{M}$ ammonium acetate buffer ( $\mathrm{pH} 5.5)$, which was then added to the DOTA-conjugated peptide solution (approximately $25-35 \mu \mathrm{g}$ in $20 \mu \mathrm{L}$ of $0.1 \mathrm{~N}$ ammonium acetate buffer). The vial was subsequently sealed and heated for $5-10$ minutes at $95^{\circ} \mathrm{C}$ to form the radioactive ${ }^{68} \mathrm{Ga}$-DOTA-peptide complex. The overall synthesis time was approximately 20-25 minutes. The radiochemical yield of the 
tracers, which was determined by radio-TLC, was $>95 \%$, and the molar activity of the solution was 185.09 $\pm 13.5 \mathrm{GBq} / \mu \mathrm{mol}$. The radiochemical purity (RCP) was $>95 \%$, as determined by HPLC. Solution stability experiments were performed to demonstrate that ${ }^{68} \mathrm{Ga}$-DOTA-peptide was intact before the tracer was injected into tumour-bearing mice. DOTA-conjugated peptides remained stable for at least 2 hours (only 5$6 \%$ of the ${ }^{68} \mathrm{Ga}$ was dissociated from the DOTA complex, supplementary Fig. S3).

\section{Biolayer interferometry (BLI)}

An eight-channel Octet RED96 BLI system (ForteBio, Menlo Park, California) was used to conduct the titration binding experiments at room temperature with shaking at $1000 \mathrm{rpm}$. Due to the small size of the peptide tracers, Super Streptavidin tips ("SSA," ForteBio, Pall Life Sciences) were used for biotinylated FAP protein loading in these binding assays; the tips were hydrated for at least 30 minutes in PBS buffer, loaded with biotinylated FAP in PBS buffer for $180 \mathrm{~s}$, and moved to baseline buffer to wash unbound biotinylated FAPs as a baseline step (60 s). Then, the biotinylated FAP was associated with sequentially diluted tracers (from $5 \mu \mathrm{M}$ to $150 \mu \mathrm{M}$ ) in a $200 \mu \mathrm{L}$ volume in black 96-well plates (association step, 720 s). Finally, the tips were submerged in baseline buffer for dissociation analysis (300 s); the association and dissociation profiles were obtained for data fitting analysis with Octet Data Analysis software (9.0.0.6.). The control study with tips with no peptides was also conducted in parallel, and the results showed low nonspecific binding. The average values were subtracted for later kinetic binding analysis. The mathematical model used assumes a simple 1:1 stoichiometry, with only one analyte in solution binding to one binding site on the surface. A Savitzky-Golay filter was applied to smooth the data.

\section{Cell line}

U87MG cells, a human glioblastoma cell line, were purchased from Bioresource Collection and Research Center (BCRC, Hsinchu, Taiwan) and maintained in minimum essential Eagle's medium (MEM) with 2 mM glutamine, $0.1 \mathrm{mM}$ nonessential amino acids, $1 \mathrm{mM}$ sodium pyruvate, 100 units $/ \mathrm{ml}$ penicillinstreptomycin and $10 \%$ FBS. The cells were cultured as an adherent monolayer in an incubator with a $5 \%$ $\mathrm{CO}_{2} / 95 \%$ air atmosphere at $37^{\circ} \mathrm{C}$. All media and reagents were purchased from Thermo Fisher Scientific (Thermo Fisher Scientific, Waltham, MA, USA).

\section{Cell-based uptake and competition studies}

Briefly, U87MG glioma tumour cells were seeded in 24-well plates. When the cells reached 80 to $90 \%$ confluence, $18.5 \mathrm{kBq}$ of radiolabelled tracers were added to each well in $0.5 \mathrm{ml}$ of Hank's buffered salt solution (HBSS) for different times (15 min, $30 \mathrm{~min}, 60 \mathrm{~min}, 90 \mathrm{~min}$ and $120 \mathrm{~min}$ ). Furthermore, competition assays were performed by incubating $2 \times 10^{5}$ U87MG cells in 24 -well plates with ${ }^{68} \mathrm{Ga}$-labelled 
tracers $(\sim 18.5 \mathrm{kBq})$ and various concentrations of cold FAPI- 04 tracers in the medium at $37^{\circ} \mathrm{C}$ for $1 \mathrm{~h}$. In all experiments, the cells were washed twice with $1 \mathrm{~mL}$ of ice-cold PBS and dissolved in lysis buffer containing $0.2 \mathrm{M} \mathrm{NaOH}$ and $1 \%$ SDS. The remaining cell-bound radioactivity after washing was determined by gamma counting (Cobra II, Packard Instruments, Downers Grove, IL) as counts per minute (CPM) and calculated as the percentage of the applied dose. All experiments were performed in triplicate and repeated three times. The binding affinity value was calculated by fitting the data with nonlinear regression using Prism6 (GraphPad software).

\section{Subcutaneous tumour xenografts}

All experiments were conducted according to a protocol approved by the Institutional Animal Care and Use Committee (IACUC) of the Laboratory Animal Center, Chang Gung Memorial Hospital, Taiwan. Female BALB/c nude mice, 6 to 8 weeks old, were obtained from the National Laboratory Animal Center (Taipei, Taiwan) and housed under a regular $12 \mathrm{~h}$ light/dark schedule. Food and water were available ad libitum. A subcutaneous tumour model was established by inoculation of $5 \times 10^{6}$ U87-MG tumour cells in exponential phase into the front flank or shoulder region. When the tumours reached a volume of approximately $300-900 \mathrm{~mm}^{3}\left(0.5 \times\right.$ length $\times$ width $\left.^{2}\right)$, the mice were ready for in vivo imaging experiments.

\section{Small-animal PET/CT imaging of tumours}

PET imaging of mice was performed by using nano PET/CT (Mediso Medical Imaging Systems). For PETbased monitoring of tumour-targeting capability, radiotracers ([68 Ga]Ga-FAPI-04, [ $\left.{ }^{68} \mathrm{Ga}\right] \mathrm{Ga}$-DOTA-FAPtp, and $\left[{ }^{68} \mathrm{Ga}\right] \mathrm{Ga}$-Alb-FAPtp-01) were administered as a bolus in phosphate-buffered saline at an activity dose of approximately $14 \mathrm{MBq}$ by rapid manual tail vein injection in situ to assess the xenograft status. For tracer imaging evaluation, dynamic ( $1 \mathrm{~h}$ for $\left[{ }^{68} \mathrm{Ga}\right] \mathrm{Ga}-F A P I-04$ and $\left.\left[{ }^{68} \mathrm{Ga}\right] \mathrm{Ga}-D O T A-F A P t p\right)$ and serial static (for [ ${ }^{68} \mathrm{Ga}$ ]Ga-Alb-FAPtp-01) PET images were acquired at $10 \mathrm{~min}, 15 \mathrm{~min}$ and $20 \mathrm{~min}$ at 1 hour, 2 hours and 3 hours post-injection. Animals were anaesthetized using $2.0 \%$ isoflurane (Benson Medical Industries, Markham, ON, Canada) prior to and during imaging. All images were generated with scatter correction, random correction and attenuation correction (AC). CT images were acquired on a smallanimal Nano CT (Mediso Medical Imaging Systems) scanner with an 8.5-cm axial-by-5.0-cm transaxial field of view. Coregistered PET/CT images were recorded and mapped to a matrix with PMOD image analysis software, version 4.0 (PMOD Technologies Ltd., Zurich, Switzerland). We determined the regions of interest (ROIs) by determining $50 \%$ of the maximum minus minimum activity level in the coronal plane of fused CT images, and we determined the ROls of muscles by analysing the shoulder muscle using PMOD image analysis software, version 4.0 (PMOD Technologies Ltd., Zurich, Switzerland). The average radioactivity concentration within the tumour or organ of interest was calculated semiquantitatively as a percentage of the administered activity per gram of tissue $(\% \mathrm{ID} / \mathrm{g})$ or as the standard uptake value (SUV) 
$\left(\mathrm{SUV}_{\text {mean }}\right)$. Maximum intensity projection (MIP) images were created by collapsing across one dimension with the maximum value in each column of voxels. The imaging ROI-derived tumour-to-normal organ radioactivity ratios, which were calculated for organs such as the muscles, heart, lung, liver, kidney and brain, were also calculated for comparisons.

\section{Ex vivo histological analysis and autoradiography}

To investigate the expression level of FAP histologically, immunohistochemistry and autoradiography were conducted to confirm the colocalization of activated FAP and the accumulation of the imaging agents. The tumour tissues were embedded in OCT compound (Tissue-Tek), snap-frozen in a dry iceisopentane slurry and stored at $-80^{\circ} \mathrm{C}$. The tissue samples were cut into $10 \mu \mathrm{m}$ thick sections, which were then stained with primary antibodies against FAP (rabbit anti-human; AB28244). Staining for FAP was performed by immunohistochemistry on histologic sections that were fixed in $4 \%$ paraformaldehyde and incubated with anti-FAP monoclonal antibodies (dilution, 1:200 in Tris buffer) at $4{ }^{\circ} \mathrm{C}$ overnight. After washing with PBS, the slides were incubated with a biotinylated goat anti-rabbit IgG secondary antibody for $1 \mathrm{~h}$ at room temperature. Streptavidin-conjugated peroxidase (ABC Elite, Vector Laboratories) was applied, and the reaction was developed by staining with 3,3'-diaminobenzidine (Sigma). The autoradiogram images were collected by a Cyclone Pulse Storage Phosphor system (Perkin-Elmer, USA) with an exposure time of $24 \mathrm{~h}$. The white-light pictures of these tumour sections were taken by a Leica MZ75 (Leica Inc., Germany) high-performance stereomicroscope equipped with a $2.5 \times$ Plano objective.

\section{Statistical analysis}

Quantitative data are expressed as the mean with standard deviation ( $\pm S D$ ). All data were analysed with GraphPad Prism 6 statistical software. Student's $t$ test was used to analyse the differences between the control group and the experimental group. A $p$-value less than 0.05 was considered statistically significant.

\section{Results}

\section{Chemistry and radiochemistry}

${ }^{68} \mathrm{Ga}^{3+}$ was used under previously reported radiolabelling conditions to radiolabel FAPI-04 and generate FAP-targeting peptides with the chelator DOTA, with high radiochemical purity (>95\%), as validated by analytic radio-HPLC. The molar radioactivity of all tracers was estimated to be $\sim 185.09 \pm 13.5 \mathrm{GBq} / \mu \mathrm{mol}$. The octanol/water partition coefficient (logP) was calculated as -2.92 (FAPI-04), -2.64 (FAPtp) and -2.88 (Alb-FAPtp-01), and the negative log $p$ values indicate the high hydrophilicity of all tracers. Higher hydrophilicity is desirable for PET tracer design to reduce radioexposure, since the radioligands will 
quickly wash out through the urine. The proposed FAP tracers all demonstrated low liver uptake, which might be due to the PEGylating linker and highly hydrophilic peptide residues. The purity of all radiolabelled tracers was sufficient; thus, the tracers were passed through a $0.22 \mu \mathrm{m}$ syringe filter for the following in vitro cell binding affinity assay or in vivo animal imaging studies without further purification.

\section{Binding specificity/affinity}

To elucidate and quantify the kinetic binding ability of FAP with the proposed peptide tracers, a fast, realtime, high-throughput and label-free analysis method based on BLI was performed (Fig. 2). In these experiments, the association profile of FAP-04 was determined as an inhibitor, and the binding signals gradually increased over time and had a minimal dissociation drop pattern. The $\mathrm{K}_{\mathrm{d}}$ value was determined as $17.4 \pm 3 \times 10^{-6} \mathrm{M}$ with BLI. However, the Alb-FAPtp-01 peptide tracers demonstrated the typical quick upand-down profile pattern of small molecules with fast association and dissociation rates, and the $\mathrm{K}_{\mathrm{d}}$ value was calculated as $18.5 \pm 2.4 \times 10^{-6} \mathrm{M}$. Due to the potential cleavage site (-Gly-Pro-) of FAP in the FAPtp peptides, the association rate of FAP is quite different than those the other two tracers. The association rate quickly increased, similar to Alb-FAPtp-01, at the early time points, but instead of reaching a plateau, the signals gradually increased over time but were not as high as those of FAP-04. This complex association pattern might be due to the peptide being cleaved by the FAP enzyme and cannot be simply determined by a 1:1 or 1:2 stoichiometry. These results were also confirmed with proteomic analysis experiments, in which the FAPtp peptide was found to be cleaved into two fragments when incubated with FAP enzymes, but the other two tracers were found to be intact under the same processing conditions (Supplementary Fig. S4). When DPP4 was used in this binding assay, only FAPI-04 demonstrated low binding and a quick dissociation profile, with a Kd value of $2.55 \times 10^{-4} \mathrm{M}\left(\mathrm{R}^{2}=0.96\right)$ (Fig. 2b). FAPtp and Alb-FAPtp-01 both demonstrated nonspecific binding throughout the experimental period. All these data indicated the specificity of the developed peptide tracers.

\section{In vitro cell uptake and competition assays}

The upregulated FAP expression in U87MG cells was confirmed by western blotting (Fig. 3 (a)) Then, the cellular uptake of $\left[{ }^{68} \mathrm{Ga}\right] \mathrm{Ga}-F A P I-04,\left[{ }^{68} \mathrm{Ga}\right] \mathrm{Ga}$-FAPtp and $\left[{ }^{68} \mathrm{Ga}\right] \mathrm{Ga}$-Alb-FAPtp-01 into U87MG cells was examined. In the cellular uptake experiment, U87MG cells were seeded into 24-well plates at a density of 0.5 million cells per well and incubated overnight. The cellular uptake was normalized to total added radioactivity. All tracers demonstrated comparable and specific cell uptake within 30 min of incubation and plateaued afterward, and $\left[{ }^{68} \mathrm{Ga}\right] \mathrm{Ga}-\mathrm{Alb}$-FAPtp-01 showed slightly higher cellular uptake $(>2 \%)$ at 120 min but did not reach statistical significance (Fig. 3b). Note that the cellular uptake protocol used in this study does not distinguish between cell surface-bound and internalized radioactivity. In the competition study, the half maximal inhibitory concentrations $\left[\mathrm{IC}_{50}\right]$ of $\left[{ }^{68} \mathrm{Ga}\right] \mathrm{Ga}-\mathrm{FAPI}-04,\left[{ }^{68} \mathrm{Ga}\right] \mathrm{Ga}-\mathrm{FAPtp}$ and 
$\left[{ }^{68} \mathrm{Ga}\right]$ Ga-Alb-FAPtp-01 were $2.489 \mathrm{nM}, 1.197 \mathrm{nM}$ and $25.76 \mathrm{nM}$, respectively (Fig. 3c). The inhibition value of $\left[{ }^{68} \mathrm{Ga}\right] \mathrm{Ga}-\mathrm{FAPI}-04$ was similar to that reported in previous papers [28]; however, a 10 -fold higher concentration of FAPI-04 was needed to block the cellular uptake of $\left[{ }^{68} \mathrm{Ga}\right] \mathrm{Ga}$-Alb-FAPtp-01, indicating that Alb-FAPtp-01 may have a stronger ability to bind to U87MG cells than FAPI-04.

\section{Dynamic PET imaging analysis of $\left[{ }^{68} \mathrm{Ga}\right] \mathrm{Ga}-\mathrm{FAPI}-04$ and $\left[{ }^{68} \mathrm{Ga}\right] \mathrm{Ga}-\mathrm{DOTA}$-FAPtp}

Armed with promising data from in vitro assays, we were able to proceed with radiolabelling and evaluation of the FAP tracers in animal models with PET. [ $\left.{ }^{68} \mathrm{Ga}\right] \mathrm{Ga}$-FAPI-04 is believed to be a highly selective and potent FAP ligand $\left(\mathrm{IC}_{50}=6.5 \mathrm{nM}\right)$ and has emerged as a lead PET imaging agent [15-16] that might compensate for the functional role that has been dominated by ${ }^{18} \mathrm{~F}-\mathrm{FDG}$ in recent decades. $\left[{ }^{68} \mathrm{Ga}\right] \mathrm{Ga}-\mathrm{FAPI}-04$ has been proven to be highly correlated with FAP expression status clinically and was used as a reference tracer in this study. To validate the efficacy of the proposed $\left[{ }^{68} \mathrm{Ga}\right] \mathrm{Ga}$-DOTA-FAPtp tracer, 1-hour dynamic PET imaging of $\left[{ }^{68} \mathrm{Ga}\right] \mathrm{Ga}$-DOTA-FAPtp and potent FAP-targeting $\left[{ }^{68} \mathrm{Ga}\right] \mathrm{Ga}$-FAPI-04 tracers was acquired and compared side by side (see Supplementary Movies S1 \& S2). After intravenous injection of both tracers, very good overall tumour radioactivity uptake and rapid whole-body washout patterns were observed (Fig. 4a). The time-activity curve of U87MG tumours displayed rapid peak uptake of both tracers, with approximately 1 standardized uptake value (SUV) by $10 \mathrm{~min}$, but [ ${ }^{68} \mathrm{Ga}$ ] Ga-DOTAFAPtp showed a delayed signal decline during the 20-40 min period, with a tumour uptake value of 0.5 SUV compared with 0.42 SUV for $\left[{ }^{68} \mathrm{Ga}\right] \mathrm{Ga}$-FAPI-04 (Fig. 4b). In addition to the higher tumour uptake observed for $\left[{ }^{68} \mathrm{Ga}\right] \mathrm{Ga}-\mathrm{FAPtp}$, there was a much faster washout rate in the two major excretion organs, kidneys and liver, especially in the liver, and the clearance rate of $\left[{ }^{68} \mathrm{Ga}\right] \mathrm{Ga}$-FAPtp was 3-fold faster than that of $\left[{ }^{68} \mathrm{Ga}\right] \mathrm{Ga}-\mathrm{FAPI}-04$, which may be due to the hydrophilic PEGylation linker of $\left[{ }^{68} \mathrm{Ga}\right] \mathrm{Ga}$-FAPtp that accelerated the tracer excretion time (Fig. 5). In addition, the higher heart accumulation signals indicated the longer plasma half-life of $\left[{ }^{68} \mathrm{Ga}\right] \mathrm{Ga}-F A P t p$. For brain and muscle tissues, the potential adverse side effects were minimal, as evidenced by indistinguishably low tracer uptake (SUV $=0.03$ and 0.042 , respectively) at late time points. These preclinical imaging results proved that the proposed FAP-targeting peptide tracer may be an effective positron emission tomography radioligand for quantifying FAP expression levels in U87MG tumours. The continuous washout of radioactivity occurred mostly through the renal pathway. Collectively, $\left.{ }^{68} \mathrm{Ga}\right] \mathrm{Ga}$-FAPtp peptide tracers bound reversibly to FAP and demonstrated comparable or even higher tumour targeting capability and more favourable biodistribution profiles than $\left[{ }^{68} \mathrm{Ga}\right] \mathrm{Ga}-\mathrm{FAPI}-04$ and thus warrant further improvements in follow-up tracer development studies.

\section{In vitro albumin binding affinity and in vivo pharmacokinetics of $\left[{ }^{68} \mathrm{Ga}\right] \mathrm{Ga}-\mathrm{Alb}-\mathrm{FAPtp}-01$}


The major focus of this work was to modify and optimize current FAPI derivative-based tracers, such as FAPI-04, FAPI-21, and FAPI-46, to prolong tumour retention and improve the tumour-to-normal ratio based on the structural framework of the peptides, eventually making them potential theranostic agents.

Therefore, we designed and synthesized prototypic $\left[{ }^{68} \mathrm{Ga}\right] \mathrm{Ga}$-FAPtp-targeted PET imaging agents with critical features of the peptide substrate and experimentally substantiated these agents. However, the prototype $\left[{ }^{68} \mathrm{Ga}\right] \mathrm{Ga}$-FAPtp tracer exhibited a rapid washout rate; thus, an intriguing in situ albumin binding strategy was incorporated into the tracer design with 4-p-chlorophenyl butyric acid. The concept of optimizing the tracer pharmacokinetic profile and prolonging tracer stability in the plasma has been proven to be effective for several published PSMA-relevant tracers. With adoption of the albumin-binding agent 4-p-chlorophenyl butyric acid, $\left[{ }^{68} \mathrm{Ga}\right]$ Ga-Alb-FAPtp-01 was first validated via in vitro FAP binding (Fig. 2), tumour cellular uptake (Fig. 3-b), albumin binding assays and in vivo half-life experiments (Fig. 6). The HSA binding affinity can reach a Kd value of $1.9 \mu \mathrm{M}$, and the half-life of the $\left[{ }^{68} \mathrm{Ga}\right] \mathrm{Ga}$-Alb-FAPtp-01 tracer in living animals was calculated to be approximately 120 mins, which reflected a significantly prolonged circulation time for such small peptide constructs that usually have circulation times of less than 10 min. Overall, these results demonstrated the high selectivity and albumin binding ability of the tracer, which may substantially enhance the opportunity for higher tumour uptake due to the long retention time in the plasma.

\section{In vivo PET imaging evaluation of $\left[{ }^{68} \mathrm{Ga}\right] \mathrm{Ga}-\mathrm{Alb}-\mathrm{FAPtp}-01$}

Therefore, intravenous administration of the optimized albumin binding $\left[{ }^{68} \mathrm{Ga}\right] \mathrm{Ga}$-Alb-FAPtp-01 tracer for PET/CT imaging was conducted to validate the FAP-targeting specificity. The imaging results showed profound rapid tumour uptake followed by moderately slow washout compared with the non-albuminbinding $\left[{ }^{68} \mathrm{Ga}\right] \mathrm{Ga}$-FAPI-04 and $\left[{ }^{68} \mathrm{Ga}\right] \mathrm{Ga}-F A P t p$ peptide tracers (Fig. 7). The peak tumour uptake reached an SUV of 1.775 and subsequently slightly declined to 1.425 SUV at $180 \mathrm{~min}$ after injection. The percentage of radioactivity in the heart represented by the circulating tracers decreased to approximately $63.154 \pm 1.779 \%$ within the initial 30 min scan interval and thereafter slowly decreased to $\sim 12.334 \pm 3.052 \%$ at the end of the scan $(180 \mathrm{~min}$ ), indicating that 4-p-chlorophenyl butyric acid played a role in optimizing the pharmacokinetics of the tracers. The tumour margins were visualized at early time points but may be confused with nonspecific perfusion imaging; thus, the persistent tracer signals detected at 2 or 3 hours post-injection in $\left[{ }^{68} \mathrm{Ga}\right] \mathrm{Ga}$-Alb-FAPtp-01 PET imaging reflect the specificity of tumour lesion detection. Furthermore, due to the low normal uptake background, the tumour contrast ratio of tumour/muscle increased significantly from $5.904 \pm 0.824$ ( 1 hour) to $6.704 \pm 0.903$ ( 2 hour) and $9.459 \pm 1.330$ (3 hour), which indicates precise whole-tumour localization for preoperative planning and delineates the tumour margins from coregistered PET/CT imaging data with high sensitivity and high spatial resolution. 
In addition, both the $\left[{ }^{68} \mathrm{Ga}\right] \mathrm{Ga}-\mathrm{FAPI}-04$ and $\left[{ }^{68} \mathrm{Ga}\right] \mathrm{Ga}$-FAPtp tracers were quickly washed out through the kidney within $60 \mathrm{~min}$. The higher blood circulation half-life of $\left[{ }^{68} \mathrm{Ga}\right] \mathrm{Ga}$-Alb-FAPtp-01 was attributable to the albumin-binding ability, which maintained a greater availability of radioligands in the plasma. Although there was somewhat higher liver uptake, the tumour uptake of the $\left[{ }^{68} \mathrm{Ga}\right] \mathrm{Ga}$-Alb-FAPtp-01 peptide tracer was significantly improved due to the prolonged and increased availability of stable radioligands in the plasma. These results validated the FAP-targeting specificity in animals injected with $\left[{ }^{68} \mathrm{Ga}\right] \mathrm{Ga}-\mathrm{Alb}-\mathrm{FAPtp}-01$ tracers.

\section{Longitudinal monitoring of tumour growth with FAPI-targeted PET imaging}

An elevated FAP expression level in tumour neoplasia was correlated with high tumourigenic and metastatic potential and a high rate of mortality in clinical patients, justifying its use as a potential prognostic marker. To further confirm the application of imaging with tracers for staging, longitudinal PET scans were conducted. The stable $\left[{ }^{68} \mathrm{Ga}\right] \mathrm{Ga}$-Alb-FAPtp-01 PET tracer demonstrated prominent longitudinal tumour uptake in subcutaneous U87MG xenografts with sequential imaging acquisition time points at different tumour sizes/stages (tumour size from 200-870 $\mathrm{mm}^{3}$ ). The tracer uptake in malignancies was $0.540+/-0.096,1.198+/-0.155$ and $1.829+/-0.100\left(\mathrm{SUV}_{\text {mean }}\right)$ at the small, medium and large stages (late stage), respectively. The increased tumour uptake observed in PET/CT imaging was consistent with the immunostaining profile of FAP, and tumour growth was accompanied by upregulation of FAP expression levels. Overall, the developed albumin-binding FAP-targeting $\left[{ }^{68} \mathrm{Ga}\right]$ Ga-Alb-FAPtp-01 tracer was able to differentiate the malignant neoplasia of U87MG tumours, and this feature may serve as a prognostic marker to identify the specific tmour phenotype for anti-FAP therapies. These pilot studies demonstrated that $\left[{ }^{68} \mathrm{Ga}\right]$ Ga-Alb-FAPtp-01 tracers may be superior to FAPI-04 PET for phenotypic tumour imaging for patient distraction diagnosis. Furthermore, it is worth noting that albumin-binding FAPtp-01 tracers are more suitable for treatment response monitoring, with potential applications for anti-FAP interventions or combination therapy with conventional treatments, such as radiotherapy and chemotherapy drugs. These follow-up studies are currently being performed.

\section{Histopathologic analysis}

The in vivo three-dimensional (3D) PET imaging is presented as a movie (see supplementary S3), and the PET imaging was strongly correlated with ex vivo autoradiography images, suggesting that FAP can be accurately validated by the proposed $\left[{ }^{68} \mathrm{Ga}\right] \mathrm{Ga}$-Alb-FAPtp-01 PET tracer (Fig. 9). We next explored the relationship between radioactivity signal images and the ex vivo histopathologic analysis of FAP and vascular maturity (CD31-positive blood vessels) on a per-tumour basis in tumour xenograft models (Fig. 9b). U87MG xenograft tumours were collected and stained with antibodies against FAP and CD31 to evaluate FAP and vascular density by histochemistry. The PET imaging and ex vivo autoradiography 
images were compared spatially with the immunostaining data. The results demonstrated that the vascular density and resulting tumour perfusion were not directly correlated with [ ${ }^{68} \mathrm{Ga}$ ]Ga-Alb-FAPtp-01 tracer uptake, as shown in Fig. 9. After investigating the histopathologic data in greater depth, it was obvious that the tumour regions with higher FAP expression levels but relatively low vascular density (weaker CD31 immunostaining) have significantly high tracer uptake in both in vivo 3D volume-rendered PET imaging and ex vivo autoradiography. The spatial colocalization and cooccurrence of the histopathologic staining with tracer accumulation confirmed the accurate registration of FAP expression status. However, vascular function and perfusion status were not significantly related to tracer accumulation but to FAP-binding specificity. Overall, in addition to FDG, the albumin tracer $\left[{ }^{68} \mathrm{Ga}\right] \mathrm{Ga}-\mathrm{Alb}$ FAPtp-01 might provide complementary information for the noninvasive assessment of tumour status and thus support better patient stratification and subsequent monitoring of therapeutic response.

\section{Discussion}

FAP, a recognized hallmark of tumours, is a cell-surface serine protease that acts on various hormones and extracellular matrix components. FAP expression is highly upregulated in a wide variety of cancers, especially epithelial tumours, of which $90 \%$ overexpress FAP [24]. To date, massive efforts has been put into targeted diagnostic imaging and peptide receptor radionuclide therapy (PRRT) based on the identified upregulated FAP [13-18, 25-26]. However, despite this growing field of research and the finding that tumour-derived activation of FAP signalling augments aggressive behaviours in certain types of tumours, the molecular mechanisms underlying the functional roles of FAP in various tumours remain elusive. Cancer biology is far more complex than originally expected, and a deeper understanding of the causes of FAP expression and relevant complications during different stages of tumour progression must be obtained to meet the unmet needs of early tumour diagnosis, therapeutic prognosis prediction and metastasis prevention.

However, the development of FAP-targeting small molecules requires extensive organic synthesis knowledge and skills. The whole panel of small modifications of the original parent structures has to be designed and fine-tuned, and then extensive follow-up experimental tests have to be carried out both in vitro and in vivo [27-28]. For most investigators, accordingly, the more effective and easy-to-use peptidebased FAP-targeted tracer proposed here would offer an amiable choice or a key noninvasive FAP imaging strategy for tumour phenotyping, staging and/or intervention monitoring studies.

In vitro cell uptake and competition assays and in vivo translational imaging evaluation studies of FAPtargeting ligands were the major focus of the current tumour diagnosis studies. In this study, the structure and radioligand properties of FAP-targeted peptide tracers were fully elucidated. The rationale of the proposed FAP-targeted PET agents is based on the natural FAP dipeptide substrate ligand sequence (-GlyPro-), which can be synthesized by a facile SPPS procedure, as a surrogate biomarker for early detection of the functional status of FAP, with the aim of determining whether such a biomarker can be used for early detection and to phenotypic differentiation of tumours. 
Unlike most published papers using transgenic FAP-expressing HT-1080 cells, however, the permanent glioma tumour cell line U87MG was used here for in vitro and in vivo tracer evaluation. Because U87MG cells evolved from a rather heterogeneous cell population, the expression profile of FAP, tumour perfusion and interactions with surrounding tissues may be closer to those of real human tumours than those of the homogeneous HT-1080 cell population, which possesses consistent FAP protein expression. In an in vivo xenograft model, U87MG cells recruited murine fibroblast cells, which were FAP positive and resulted in specific FAP-targeted PET imaging. FAP expression is also observed in tumour vessels, and this may facilitate and enhance FAP tracer binding to the tumour vasculature, contributing to higher tracer uptake in tumours. Overall, the heterogeneous nature of U87MG cells may assist the interpretation of the tumourbinding and pharmacokinetic profiles of different tumour entities in general. This valuable information may be extrapolated to support clinical translation of FAP-based imaging evaluation or even endoradiotherapy applications.

To confirm the advantage of the newly developed tracers over widely used FAP inhibitor tracers, the proposed FAP-targeting tracers were subjected to direct head-to-head comparison with [ $\left.{ }^{68} \mathrm{Ga}\right] \mathrm{Ga}-\mathrm{FAPI}-04$, the reference FAP tracer, and both in vitro binding affinity and in vivo PET/CT image results were comparable between $\left[{ }^{68} \mathrm{Ga}\right] \mathrm{Ga}-\mathrm{FAPI}-04$ and the first prototype peptide tracer, $\left[{ }^{68} \mathrm{Ga}\right] \mathrm{Ga}$-FAPtp, in the U87MG model. The rapid overall washout rate in normal tissues and significant tumour uptake were similar for both tracers, but $\left[{ }^{68} \mathrm{Ga}\right] \mathrm{Ga}-F A P t p$ demonstrated marginally higher tumour uptake. As reported by the Weir-Torn Jiaang and Pieter Van der Veken groups [28-29], the difluorinated proline residue in the $\left[{ }^{68} \mathrm{Ga}\right] \mathrm{Ga}-\mathrm{FAPtp}$ structure can decrease the $\mathrm{Km}$ value of FAP binding due to the higher lipophilicity and better fitting. The double fluorine substitution in position 3 of the pyrrolidine ring was also reported to dramatically improve the binding potency up to 6-fold for the nitrile-based inhibitor and to improve FAP/PREP selectivity [29-30]. Taken together, these features show that difluorinated proline might be the crucial component in the current FAP-targeting tracer design. On the basis of these favourable initial assessments, we designed the albumin-binding FAP tracer $\left[{ }^{68} \mathrm{Ga}\right] \mathrm{Ga}$-Alb-FAPtp-01 to prolong the circulation time and increase the retention time in tumour lesions. Additionally, the potential cleavage site of FAP, the Gly-Pro-Trp-Gly-difluorinated Pro-OH sequence in [ $\left.{ }^{68} \mathrm{Ga}\right] \mathrm{Ga}-F A P t p$, was reduced to Trp-Glydifluorinated Pro-OH to prevent confusing imaging analysis results. Unlike the non-albumin-binding FAPI tracers ( $\left.\left[{ }^{68} \mathrm{Ga}\right] \mathrm{Ga}-\mathrm{FAP}-04,\left[{ }^{68} \mathrm{Ga}\right] \mathrm{Ga}-\mathrm{FAPtp}\right)$ for which tumour uptake was much lower and quickly washed out through the renal pathway within 1 hour, [ ${ }^{68} \mathrm{Ga}$ ]Ga-Alb-FAPtp-01 demonstrated quick and prolonged tracer accumulation in U87MG tumours, indicating that the $\left[{ }^{68} \mathrm{Ga}\right] \mathrm{Ga}-A l b-F A P t p-01$ tracers were not only targeted to FAP but also steadily diffused and transported into the tumour by the intrinsic blood vessels or internal fluid pressure due to its albumin-binding capability. Thus, the $\left[{ }^{68} \mathrm{Ga}\right]$ Ga-Alb-FAPtp-01 targeted tracer not only provides a facile strategy for tracer synthesis but also improves the pharmacokinetic profile of the $\left[{ }^{68} \mathrm{Ga}\right] \mathrm{Ga}$-FAPtp tracer with a 4-p-chlorophenyl butyric acid component for endogenous albumin-binding capability in vivo. This feature enables prolonged stability in the systemic circulation and precise marker targeting in the blood, highlighting its potential for clinical application in theranostic agent development. However, it is a concern that $\left[{ }^{68} \mathrm{Ga}\right] \mathrm{Ga}-\mathrm{Alb}$-FAPtp-01 uptake does not necessarily 
reflect only the FAP expression level but also the neovasculature of U87MG tumours due to the intrinsic blood-targeting agent in $\left[{ }^{68} \mathrm{Ga}\right]$ Ga-Alb-FAPtp-01. In fact, the kinetic profile of tracer distribution clearly demonstrates two regions: "rapid washout" and retaining regions. The higher tracer uptake in the latter region was confirmed by the immunostaining results, showing that FAP expression is upregulated but not associated with the immature and leaky vasculature; thus, the increase in tracer accumulation over time may be due to specific FAP binding (Fig. 9). Consequently, with high overall scores for pharmacokinetic performance, suitability for tumour diagnosis, and accessibility to the wider clinical and research communities, the $\left[{ }^{68} \mathrm{Ga}\right] \mathrm{Ga}$-Alb-FAPtp-01 tracer has emerged as a tracer of choice for further studies of potential clinical application. The tracer may play a role in ascertaining the links between FAP expression, disease state, and disease progression in the near future. The use of a DOTA chelator as a dual functional component that may be labelled with therapeutic radioisotopes, such as Y-90 and Lu-177, shows promise for theranostic applications, and related therapeutic effect experiments are currently underway.

\section{Conclusion}

Dynamic changes in tumour FAP expression are a characteristic marker of cancer; however, precise the protein fluctuation changes that occur and their correlations with tumour progression are not known. Thus, we try to provide an effective and noninvasive imaging strategy to advance the understanding of the functions of FAP in cancer, particularly its prognostic value for various tumour types, and as a complement to diagnostic uses, its potential theranostic application is under investigation in preclinical investigations. We highlight this unique and accessible solution to the existing limitations in the field, which could shape preclinical and clinical studies of FAP tracer development.

\section{Declarations}

\section{Acknowledgements}

The authors wish to thank for technical assistance of Instrumentation Center, Chang Gung University, Tao-Yuan, Taiwan. The authors are grateful to the staffs of Technology Commons, College of Life Science, and the Instrumentation Center sponsored by Ministry of Science and Technology, National Taiwan University.

\section{Funding information}

This work was supported by Ministry of Science and Technology of Taiwan (107-2314-B-182A-149-MY3 to C.W.H.), Chang Gung Memorial Hospital (CMRPG3K1451) and National Taiwan University (108L7866 and 109 L 7866 to F.T.H.). 


\section{Compliance with ethical standards}

\section{Conflict of interest}

The authors declare no conflicts of interest.

\section{Research involving human participants and/ or animals}

All animal experiments were performed according to a protocol approved by the Institutional Animal Care and Use Committee (IACUC) of National Taiwan University (No. NTU108-EL-00021) and Chang Gung Memorial Hospital, Linkou, Taiwan (No.201612060).

Disclaimer The current work has not been submitted for review or is not under acceptance for publication in any journal.

\section{Author Contributions}

Jia-Jia Lin contributed to in vitro cell experiments, generated figures, and contributed to in vivo animal experiments. Chia-Pao Chuang and Jia-Yu Lin contributed to biological study design, experiments, and figure generation. F.T. Huang designed and coordinated the study, wrote the manuscript, and edited the manuscript. C.W. Huang designed and coordinated the study, performed chemical experiments, generated figures, and wrote and edited the manuscript.

\section{References}

1. Fridman WH, Pagès F, Sautès-Fridman $C$, Galon J. The immune contexture in human tumours: impact on clinical outcome. Nat Rev Cancer. 2012 Mar 15;12(4):298-306.

2. Giraldo NA, Becht E, Remark R, Damotte D, Sautès-Fridman C, Fridman WH. The immune contexture of primary and metastatic human tumours. Curr Opin Immunol. 2014 Apr;27:8-15.

3. Fridman WH, Zitvogel L, Sautès-Fridman C, Kroemer G. The immune contexture in cancer prognosis and treatment. Nat Rev Clin Oncol. 2017 Dec;14(12):717-34.

4. Garner $\mathrm{H}$, de Visser KE. Immune crosstalk in cancer progression and metastatic spread: a complex conversation. Nat Rev Immunol. 2020 Aug;20(8):483-97.

5. Scanlan MJ, Raj BKM, Calvo B, Garin-Chesa P, Sanz-Moncasi MP, Healey JH, et al. Molecular cloning of fibroblast activation protein $\mathrm{a}$, a member of the serine protease family selectively expressed in 
stromal fibroblasts of epithelial cancers. Proc Natl Acad Sci U S A. 1994;91(12):5657-61.

6. Kraman M, Bambrough PJ, Arnold JN, Roberts EW, Magiera L, Jones JO, et al. Suppression of antitumor immunity by stromal cells expressing fibroblast activation protein-alpha. Science. 2010 Nov 5;330(6005):827-30.

7. Fitzgerald AA, Weiner $L M$. The role of fibroblast activation protein in health and malignancy. Cancer Metastasis Rev. 2020 Sep;39(3):783-803.

8. Kuzet SE, Gaggioli C. Fibroblast activation in cancer: when seed fertilizes soil. Cell Tissue Res. 2016 Sep;365(3):607-19.

9. Croft AP, Campos J, Jansen K, Turner JD, Marshall J, Attar M, et al. Distinct fibroblast subsets drive inflammation and damage in arthritis. Nature. 2019 Jun;570(7760):246-51.

10. Lay AJ, Zhang HE, McCaughan GW, Gorrell MD. Fibroblast activation protein in liver fibrosis. Front Biosci (Landmark Ed). 2019 Jan 1;24:1-17.

11. Hamson EJ, Keane FM, Tholen S, Schilling O, Gorrell MD. Understanding fibroblast activation protein (FAP): substrates, activities, expression and targeting for cancer therapy. Proteomics Clin Appl. 2014 Jun;8(5-6):454-63.

12. Juillerat-Jeanneret $L$, Tafelmeyer $P$, Golshayan $D$. Fibroblast activation protein-a in fibrogenic disorders and cancer: more than a prolyl-specific peptidase? Expert Opin Ther Targets. 2017 Oct;21(10):977-91.

13. Busek P, Mateu R, Zubal M, Kotackova L, Sedo A. Targeting fibroblast activation protein in cancer Prospects and caveats. Front Biosci (Landmark Ed). 2018 Jun 1;23:1933-1968.

14. Toms J, Kogler J, Maschauer S, Daniel C, Schmidkonz C, Kuwert T, et al. Targeting Fibroblast Activation Protein: Radiosynthesis and Preclinical Evaluation of an ${ }^{18} \mathrm{~F}$-Labeled FAP Inhibitor. J Nucl Med. 2020 Dec;61(12):1806-13.

15. Lindner T, Loktev A, Altmann A, Giesel F, Kratochwil C, Debus J, et al. Development of QuinolineBased Theranostic Ligands for the Targeting of Fibroblast Activation Protein. J Nucl Med. 2018 Sep;59(9):1415-22.

16. Giesel FL, Kratochwil C, Lindner T, Marschalek MM, Loktev A, Lehnert W, et al. ${ }^{68} \mathrm{Ga}$-FAPI PET/CT: Biodistribution and Preliminary Dosimetry Estimate of 2 DOTA-Containing FAP-Targeting Agents in Patients with Various Cancers. J Nucl Med. 2019 Mar;60(3):386-92.

17. Kratochwil C, Flechsig P, Lindner T, Abderrahim L, Altmann A, Mier W, et al. ${ }^{68} \mathrm{Ga}-F A P I$ PET/CT: Tracer Uptake in 28 Different Kinds of Cancer. J Nucl Med. 2019 Jun;60(6):801-5.

18. Ferdinandus J, Kessler L, Hirmas N, Trajkovic-Arsic M, Hamacher R, Umutlu L, et al. Equivalent tumor detection for early and late FAPI-46 PET acquisition. Eur J Nucl Med Mol Imaging. 2021 Feb 23. doi: 10.1007/s00259-021-05266-7. Epub ahead of print.

19. Windisch P, Zwahlen DR, Giesel FL, Scholz E, Lugenbiel P, Debus J, et al. Clinical results of fibroblast activation protein (FAP) specific PET for non-malignant indications: systematic review. EJNMMI Res. 2021 Feb 19;11(1):18. 
20. Moon ES, Elvas F, Vliegen G, De Lombaerde S, Vangestel C, De Bruycker S, et al. Targeting fibroblast activation protein (FAP): next generation PET radiotracers using squaramide coupled bifunctional DOTA and DATA ${ }^{5 m}$ chelators. EJNMMI Radiopharm Chem. 2020 Jul 29;5(1):19.

21. Kuo HT, Lin KS, Zhang Z, Uribe CF, Merkens H, Zhang C, et al. Novel ${ }^{177}$ Lu-labeled Albumin-binderconjugated PSMA-targeting Agents with Extremely High Tumor Uptake and Enhanced Tumor-tokidney Absorbed Dose Ratio. J Nucl Med. 2020 Aug 28:jnumed.120.250738.

22. Pang HH, Chen PY, Wei KC, Huang CW, Shiue YL, Huang CY, et al. Convection-Enhanced Delivery of a Virus-Like Nanotherapeutic Agent with Dual-Modal Imaging for Besiegement and Eradication of Brain Tumors. Theranostics. 2019 Feb 28;9(6):1752-1763.

23. Huang CW, Chang YH, Lee HH, Wu JY, Huang JX, Chung YH, et al. Irisin, an exercise myokine, potently suppresses tumor proliferation, invasion, and growth in glioma. FASEB J. 2020 Jul;34(7):9678-93.

24. Lee HO, Mullins SR, Franco-Barraza J, Valianou M, Cukierman E, Cheng JD. FAP-overexpressing fibroblasts produce an extracellular matrix that enhances invasive velocity and directionality of pancreatic cancer cells. BMC Cancer. 2011 Jun;13:11:245.

25. Lindner T, Altmann A, Krämer S, Kleist C, Loktev A, Kratochwil C, Giesel F, Mier W, Marme F, Debus J, Haberkorn U. Design and Development of ${ }^{99 \mathrm{~m}}$ TC-Labeled FAPI Tracers for SPECT Imaging and ${ }^{188} \mathrm{Re}$ Therapy. J Nucl Med. 2020 Oct;61(10):1507-13.

26. Loktev A, Lindner T, Burger EM, Altmann A, Giesel F, Kratochwil C,et al. Development of Fibroblast Activation Protein-Targeted Radiotracers with Improved Tumor Retention. J Nucl Med. 2019 Oct;60(10):1421-9.

27. Jansen K, Heirbaut L, Verkerk R, Cheng JD, Joossens J, Cos P, et al. Extended structure-activity relationship and pharmacokinetic investigation of (4-quinolinoyl)glycyl-2-cyanopyrrolidine inhibitors of fibroblast activation protein (FAP). J Med Chem. 2014a;57(7):3053-74.

28. Edosada CY, Quan C, Wiesmann C, Tran T, Sutherlin D, Reynolds M, et al. Selective inhibition of fibroblast activation protein protease based on dipeptide substrate specificity. J Biol Chem. 2006;281(11):7437-44.

29. Tsai TY, Yeh TK, Chen X, Hsu T, Jao YC, Huang CH, et al. Substituted 4-carboxymethylpyroglutamic acid diamides as potent and selective inhibitors of fibroblast activation protein. J Med Chem. 2010 Sep 23;53(18):6572-83.

30. De Decker A, Vliegen G, Van Rompaey D, Peeraer A, Bracke A, Verckist L, et al. Novel Small MoleculeDerived, Highly Selective Substrates for Fibroblast Activation Protein (FAP). ACS Med Chem Lett. 2019 Jul;9(8):1173-9. 10(.

\section{Figures}


a

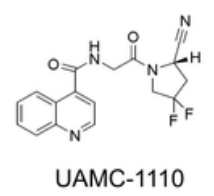

b

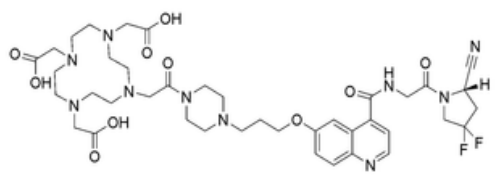

FAPI-04
C

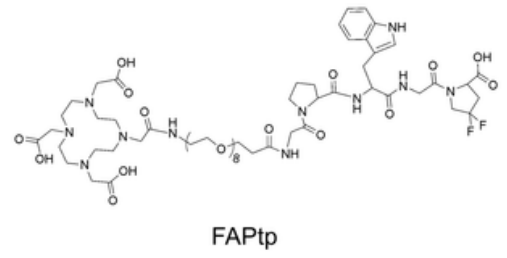

d

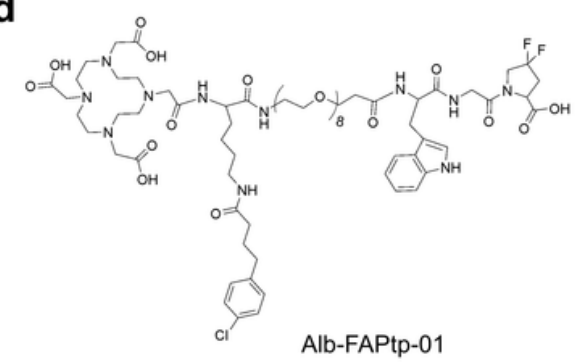

Fig. 1 Representative chemical structures of (a) UAMC-110, (b) FAPI-04 and the developed peptide tracers (c) FAPtp and (d) Alb-FAPtp-01

\section{Figure 1}

\section{[See figure]}

a

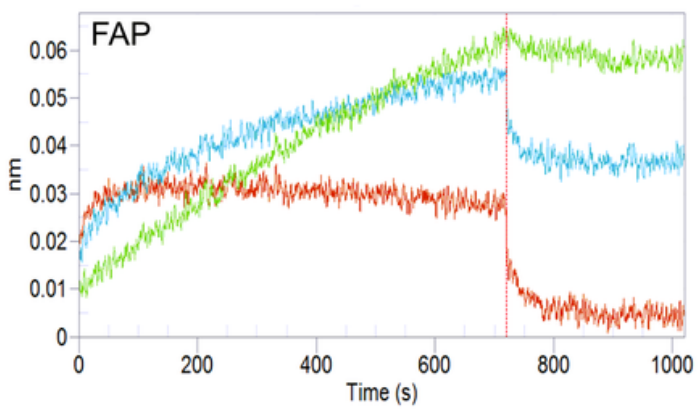

b

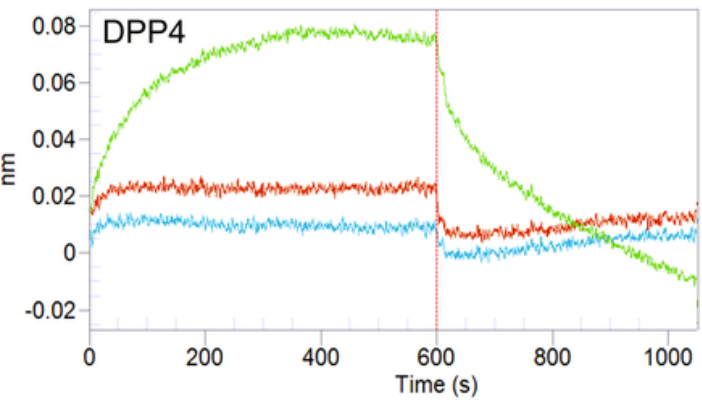

FAPI-04 FAPtp Alb-FAPtp

Fig. 2 Validation of FAPI-04, FAPtp and Alb-FAPtp-01 tracer binding to (a) FAP and (b) DPP4, assayed with BLI. The FAP and DPP4 proteins were loaded into the sensor tip from a $10 \mathrm{nM}$ solution and then incubated with various concentrations of labelled free FAP tracers in binding buffer. The association and dissociation binding curves were monitored with an eight-channel Octet RED96 BLI system and Kd values were calculated with Octet Data Analysis software (9.0.0.6.) (green: FAPI-04, blue: FAPtp, red: Alb-FAPtp-01.) 
Figure 2

[See figure]

a

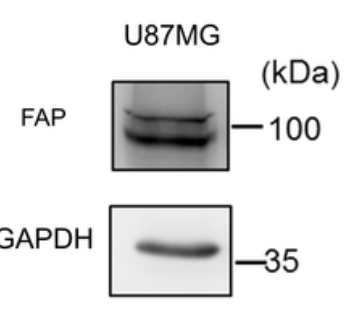

b

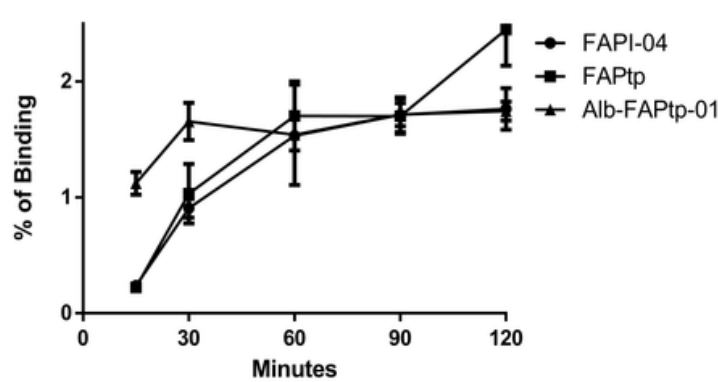

C

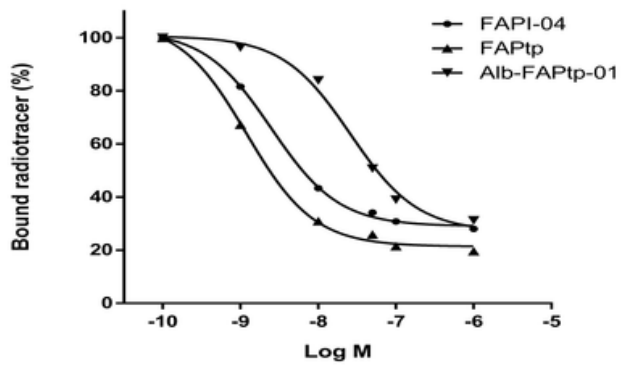

Fig. 3 FAP expression and cell binding and inhibition assay. (a) The western blot results confirmed FAP expression and GAPDH was used as internal control. (b) Cell uptake assay of FAPI-04, FAPtp and Alb-FAPtp-01 tracers. (c) Inhibition of FAPI-04, FAPtp and Alb-FAPtp-01 tracers binding to FAP in U87MG cells by nonradiolabelled inhibitor, FAPI-04 ( $\mathrm{n}=3$, mean \pm SD).

\section{Figure 3}

[See figure] 


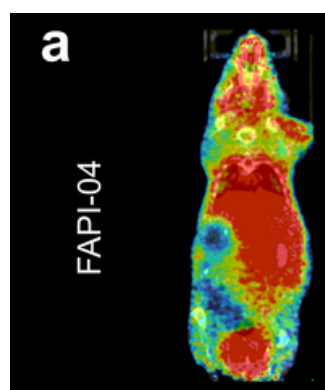

0-5

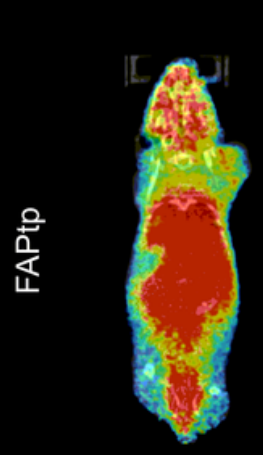

0-5

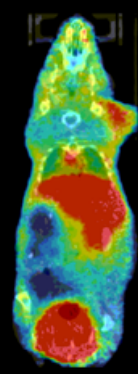

5-20

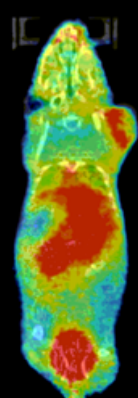

5-20

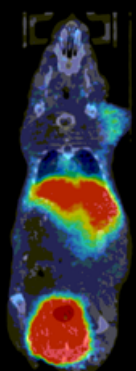

20-40

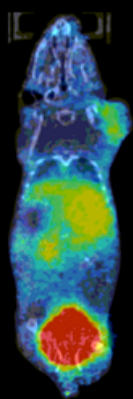

20-40

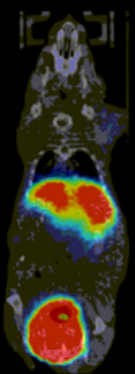

40-60 min

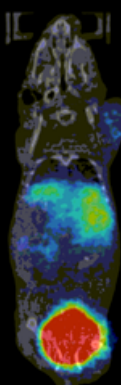

40-60 min b

\section{SUV}

0.8
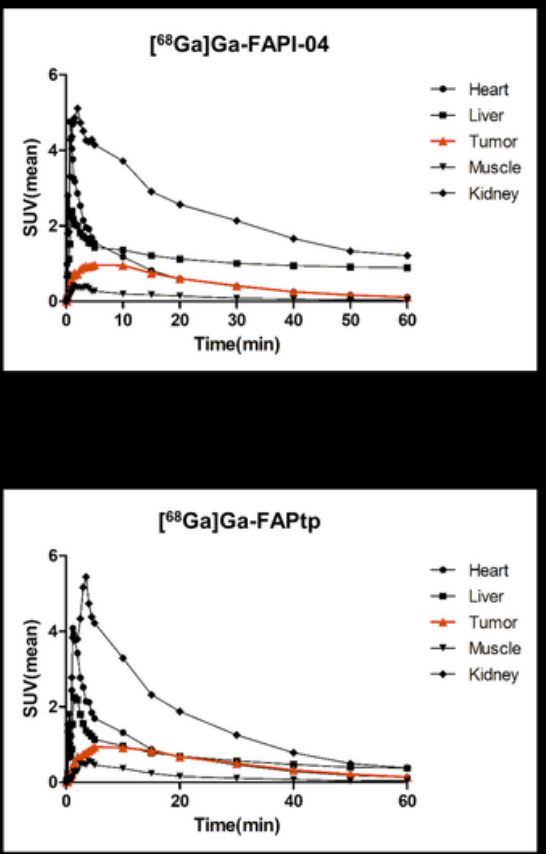

0.1

Fig. 4 (a) Dynamic PET imaging of $\left[{ }^{68} \mathrm{Ga}\right] \mathrm{Ga}-F A P I-04$ and $\left[{ }^{68} \mathrm{Ga}\right] \mathrm{Ga}$-FAPtp and (b) time-activity curves of radiotracers in major organs and U87MG tumours.

Figure 4

[See figure]

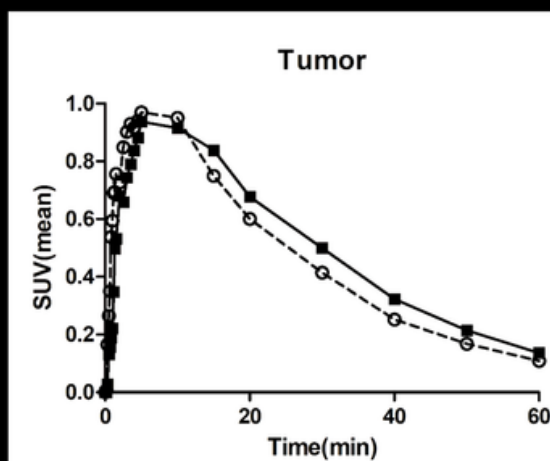

Liver

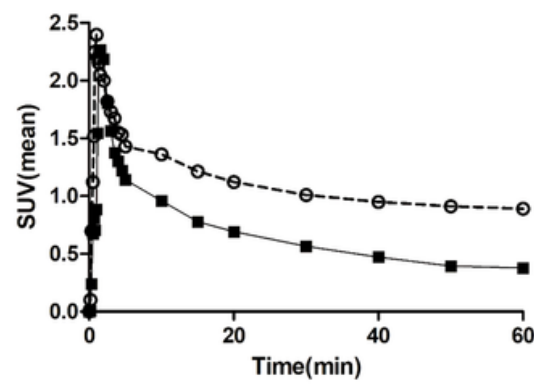

Muscle
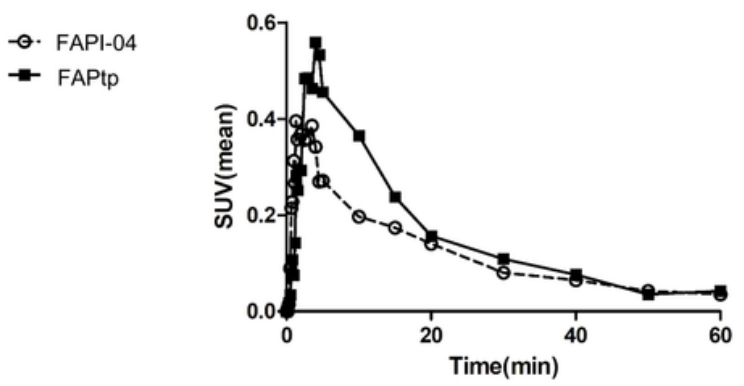

Kidney

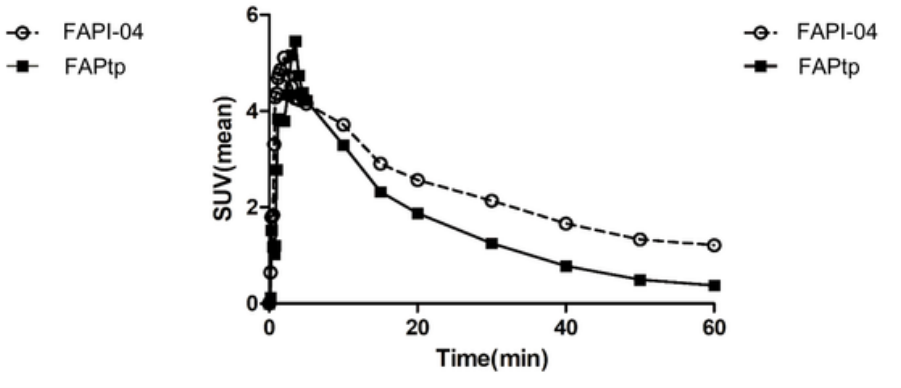

Fig. 5 Comparison of the time-activity curves of $\left[{ }^{68} \mathrm{Ga}\right] \mathrm{Ga}-F A P I-04$ and $\left[{ }^{68} \mathrm{Ga}\right] \mathrm{Ga}-F A P t p$ in major organs and U87MG tumour based on ROIs drawn from dynamic imaging data. 
Figure 5

[See figure]

\section{$\left[{ }^{68} \mathrm{Ga}\right] \mathrm{Ga}-A l b-F A P t p-01$}

a

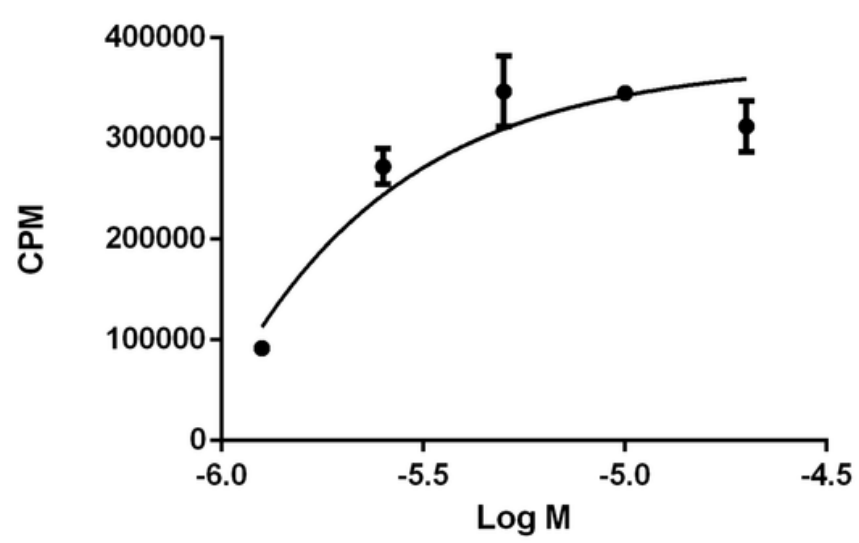

b

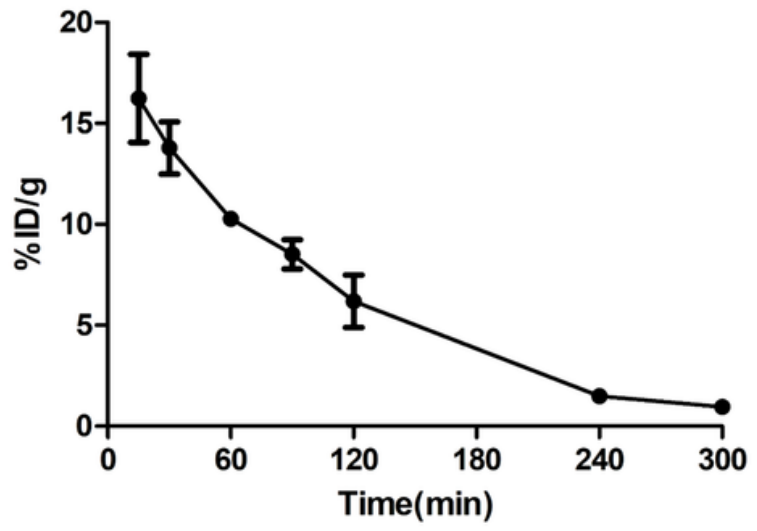

Fig. 6 (a) The albumin binding affinity assay of $\left[{ }^{68} \mathrm{Ga}\right] \mathrm{Ga}-\mathrm{Alb}-\mathrm{FAPtp}-01$. (b)The proportion of plasma-bound activity of $\left[{ }^{68} \mathrm{Ga}\right] \mathrm{Ga}-\mathrm{Alb}-\mathrm{FAPtp}-01$ in healthy nu/nu mice after injection.

\section{Figure 6}

[See figure] 


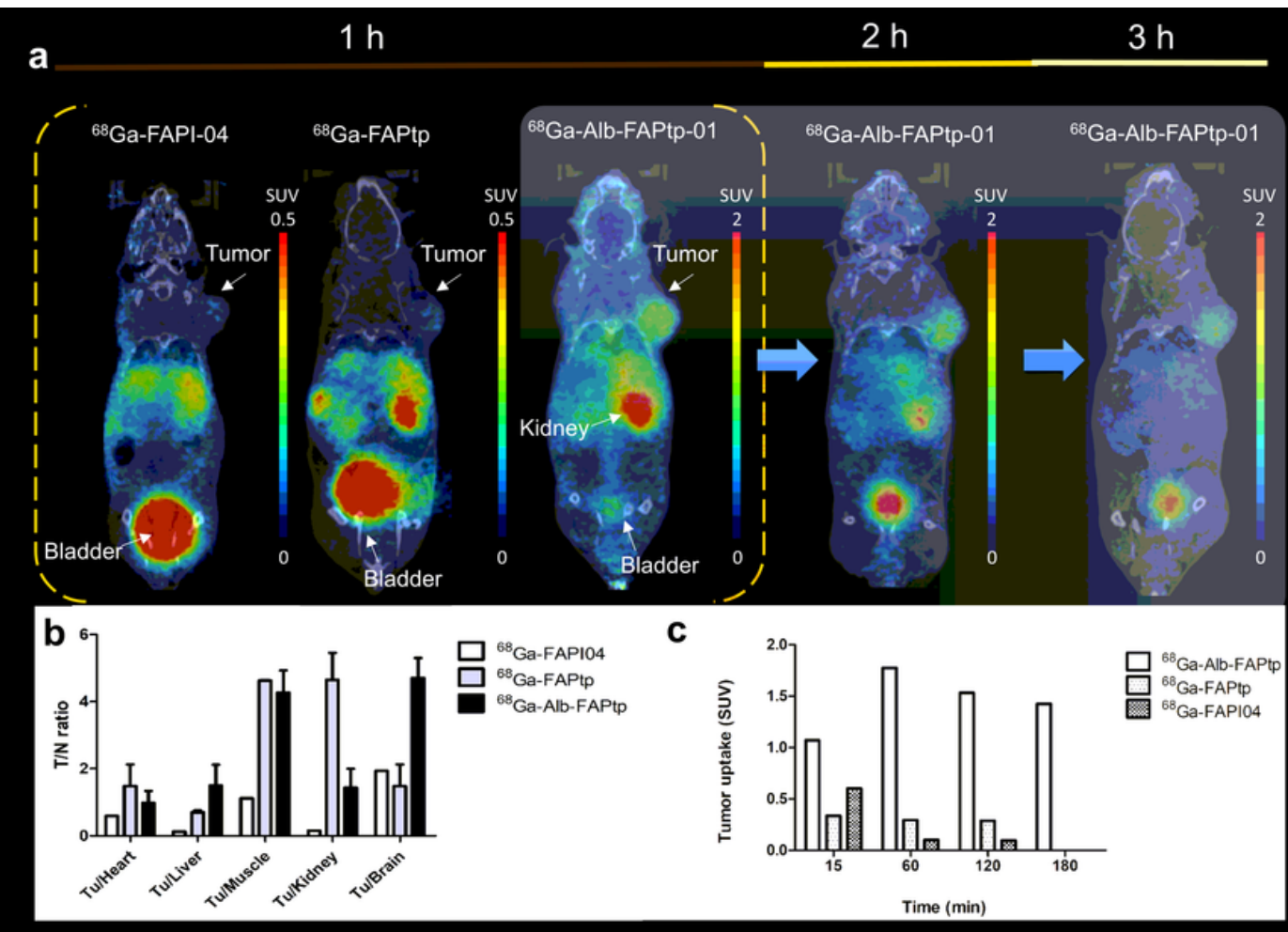

Fig. 7 (a) Representative static PET/CT imaging comparison of $\left[{ }^{68} \mathrm{Ga}\right] \mathrm{Ga}-\mathrm{FAPI}-04,\left[{ }^{68} \mathrm{Ga}\right] \mathrm{Ga}-\mathrm{FAPtp}$ and $\left[{ }^{68} \mathrm{Ga}\right] \mathrm{Ga}-\mathrm{Alb}-$ FAPtp-01 in mice with glioma xenografts after injection. (b) Tumour/organ ratio analysis of tracers. (c) Tumour uptake evaluation at selected time points ( $15 \mathrm{~min}, 60 \mathrm{~min}, 120 \mathrm{~min}$ and $180 \mathrm{~min}$ ).

\section{Figure 7}

[See figure]

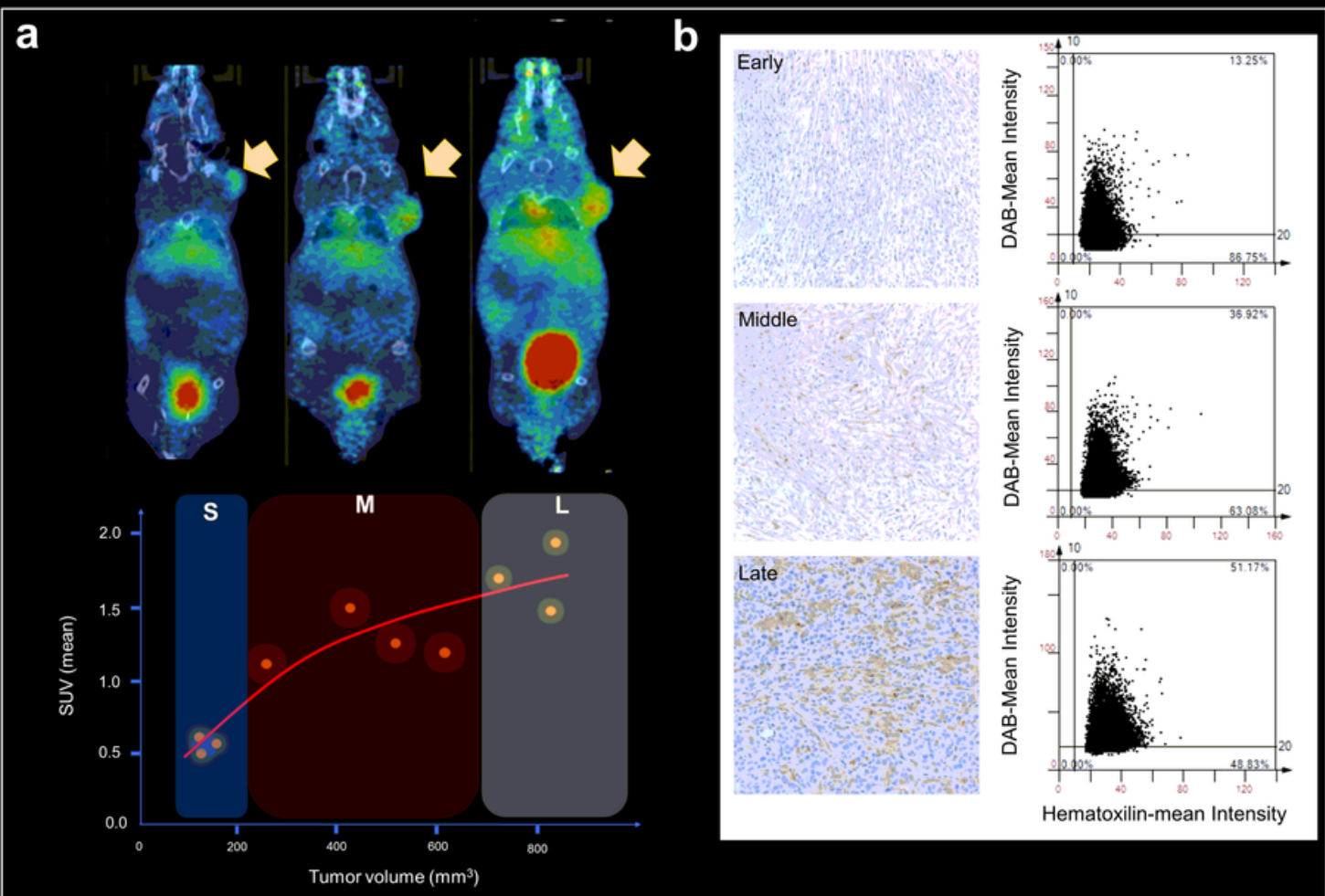

Fig. 8 (a) Longitudinal PET/CT imaging and SUV tumour uptake of $\left[{ }^{68} \mathrm{Ga}\right] \mathrm{Ga}-A l b-F A P t p-01$ in glioma xenograft mice at different tumour stages (early, middle and late). (b) Quantitative comparison of histological staining of tumour cross sections for FAP, confirming the correlation of tracer uptake with the growth status of tumour xenografts. 
Figure 8

[See figure]

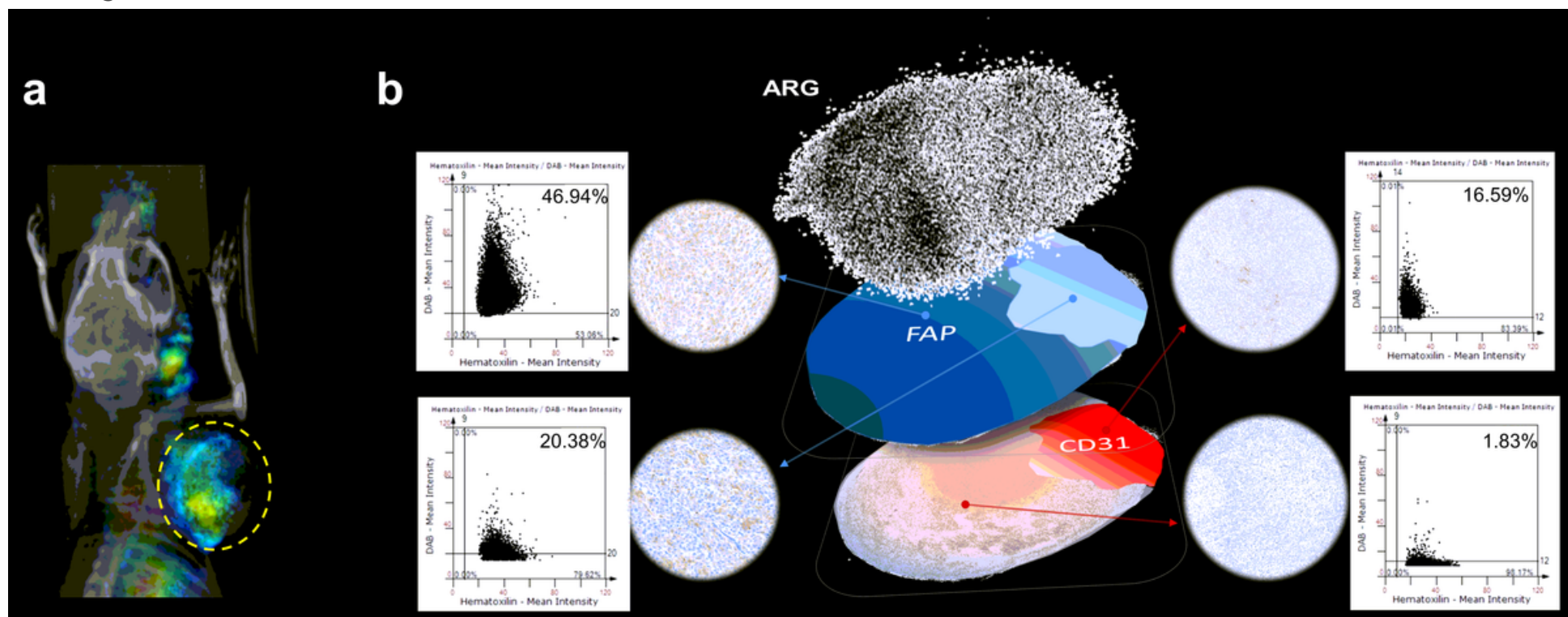

Fig. 9 (a) The 3D volume-rendered image of $\left[{ }^{68} \mathrm{Ga}\right] \mathrm{Ga}$-Alb-FAPtp-01 in mice with glioma xenografts after injection. (b) ARG image and quantitative analysis of histological staining of U87MG tumour cross sections for FAP and CD31, delineating the relationship between tracer distribution and protein expression levels.

\section{Figure 9}

[See figure]

\section{Supplementary Files}

This is a list of supplementary files associated with this preprint. Click to download.

- FAPI04MovieS1.mov

- FAPtpMOvieS2.mov

- AlbFAPtpMovieS3.mov

- Supplementarydatall.docx 